\title{
Pseudocyclops schminkei (Copepoda, Calanoida, Pseudocyclopidae): a new species from Okinawa
}

\author{
Supawadee Chullasorn • Frank D. Ferrari • \\ Hans-Uwe Dahms
}

Received: 22 October 2008 / Revised: 19 May 2009 / Accepted: 9 June 2009 / Published online: 24 July 2009

(C) Springer-Verlag and AWI 2009

\begin{abstract}
Both genders of Pseudocyclops schminkei n. sp. are described from a pearl fishery aquarium on Zamami Island, Okinawa, Japan; it is the 37th species of the genus. Pseudocyclops schminkei sp. nov. differs from other species of the magnus species group in the shape of the lobes of distal exopodal segment of the male left leg 5, and the morphology of setae on middle and distal exopodal segment of male right swimming leg 2 . Aspects of the morphology of $P$. xiphophorus and P. bilobatus are redescribed, and an unnamed Pseudocyclops sp. from the Shedd Aquarium in Chicago, IL, is briefly noted. Females of $P$. schminkei sp. nov., P. xiphophorus and Pseudocyclops sp. could not be separated from each other with the small number of specimens available in this study for the former two species.
\end{abstract}

Keywords Pseudocyclops $\cdot$ New calanoid copepod · Morphology

Communicated by H.-D. Franke.

\section{S. Chullasorn}

Department of Biology, Faculty of Science,

Ramkhamhaeng University, Bangkapi,

Bangkok 10240, Thailand

F. D. Ferrari

IZ/MSC; MRC-534, National Museum of Natural History,

Smithsonian Institution, 4210 Silver Hill Rd.,

Suitland, MD 20746, USA

H.-U. Dahms ( $\square)$

Institute of Marine Biology,

National Taiwan Ocean University,

2 Pei-Ning Road, Chi-Lung 202, Taiwan

e-mail: hansd@mail.ntou.edu.tw

\section{Introduction}

Although most calanoid copepods are planktonic, a significant calanoid fauna is associated with waters immediately above the seabed. In the deep-sea, this benthopelagic fauna is poorly known but diverse (Markhaseva and Ferrari 2005), and its elucidation is expected to require a sustained taxonomic effort (Bradford-Grieve 2004). In coastal marine habitats, benthopelagic calanoids are better known taxonomically. As a result of this knowledge, a general body architecture and limb configuration were proposed for coastal benthopelagic calanoids almost a half century ago, "small size, plump body, short antenna 1, and strong outer spines on the exopods of the swimming legs" (Bowman and González 1961: 37).

Pseudocyclops Brady, 1872 is one of the most speciose and widely distributed of the coastal benthopelagic calanoid genera. It is one of two genera along with Miheptneria Andronov, 2007 in the family Pseudocyclopidae Giesbrecht, 1893, which is one of two families along with Ridgewayiidae Wilson, 1958 in the superfamily Pseudocyclopoidea Andronov, 1974. Brady (1872) originally included the only known species that was known at that time, $P$. crassiremis Brady, 1872, in the copepod family Misophriidae because of the configuration of its well-developed first maxilla. However, copulatory openings of both males and females are paired in species of Misophriidae while males of Pseudocyclops have a single, asymmetrically positioned copulatory opening. Based on this derived attribute, Giesbrecht (1893) proposed the family Pseudocyclopidae and placed its species in Calanoida. A recent proposal (Andronov 2007) to include in the family Pseudocyclopidae, all of the species in the superfamilies Pseudocyclopoidea and Epacteriscoidea, i.e. those species belonging to the families Pseudocyclopidae, Epacteriscidae, Boholinidae and 
Ridgewayiidae, would increase the number of genera in Pseudocyclopidae to 31 .

Species of Pseudocyclops are distributed in waters immediately over the seabed from the coastal zone to the edge of the continental shelf (Andronov 1986). They are almost exclusively marine (Markhaseva and Dahms 2004), although a few species have been reported from brackish waters (Zagami et al. 2005, Brugnano et al. 2006, 2009). Among the 36 nominal species that have been assigned to Pseudocyclops, excluding 2 nominal subspecies of P. obtusatus Brady and Robertson, 1873, only P. stephoides Thompson, 1895 has been removed from the genus, to Thompsonopia Jaume, Fosshagen and Iliffe, 1999. Of the remaining 35 nominal species, 23 were described within a century after the genus was established while 12 species, about one-third, have been described in the last 35 years.

The distribution of species of Pseudocyclops is not well understood. Many species are known from a few specimens and most have been reported from only one locality. Three species known regionally are $P$. cokeri Bowman and González, 1961, P. rostratus Bowman and González, 1961, and P. rubrocinctus Bowman and González, 1961 from the Caribbean Sea and Gulf of Mexico (see Bowman and González 1961; Fosshagen 1968). Pseudocyclops obtusatus and its subspecies have been reported from the Atlantic Ocean (Brady and Robertson 1873), the Indian Ocean (Sewell 1932; Ummerkutty 1968), and the Pacific Ocean (Vervoort 1964), but the conspecificity of these specimens has been questioned (Haridas et al. 1994). Pseudocyclops xiphophorus Wells, 1967 has been reported as occurring naturally in coastal waters of the Indian Ocean off Mozambique and in Lake Faro, Sicily (see Wells 1967; Zagami et al. 2005; Brugnano et al. 2009) although neither a Lessepsian dispersion (Por 1971) nor an introduction by ship ballast water (Carlton 1985) was considered for either of these populations. A broad distribution for P. magnus Esterly, 1911 from Bermuda in the Atlantic Ocean resulted when Nicholls (1944) placed it in synonymy with P. latens Gurney, 1927 from the Red Sea, adjacent to the Indian Ocean, despite a notable difference in size between the only female specimen known for each species $(0.63 \mathrm{~mm}$ vs. $1.1 \mathrm{~mm}$ ). Yeatman (1975) described female and male specimens, which he attributed to P. magnus from St. James, Barbados, extending the distribution of this species appreciably, but again females $(0.60-0.68 \mathrm{~mm})$ were notably smaller than Esterly's specimen.

Adults of Pseudocyclops spend the greater part of the diel cycle on or near the substrate, although some copepodids may be collected in open water immediately above the seabed for short periods at night. The plump, nearly spherical shape and relatively short first antennae of the copepodid stages may limit their ability to remain in the water column. Post-embryonic development has been described for only one species, P. umbraticus Giesbrecht, 1893 (see Costanzo et al. 2004), but nothing is known about the distribution of the naupliar stages.

In this paper, we describe the new species Pseudocyclops schminkei. It is the first species reported from Okinawa and only the third species known from Japanese waters, along with $P$. australis Nicholls, 1944 reported by Tanaka from Kyushu and P. lepidotus Barr and Ohtsuka, 1989 originally described from Kyushu.

\section{Specimens and methods}

Pseudocyclops schminkei sp. nov.: female holotype (USNM 1115511), male allotype (USNM 1115512), 6 female paratypes (USNM 1115513), and 2 male paratypes (USNM 1115514) are deposited in the Crustacea collection of the Smithsonian Institution's National Museum of Natural History. They were collected with sediment from an aquarium at Kerama Pearl Ltd, a pearl fishery on Zamami Island, Okinawa, Japan on 5 January 2007; the aquarium is used to culture juvenile pearl oysters. Juvenile pearl oysters are collected locally, and maintained in local seawater that is passed through a sand filter before entering the aquarium. In addition to any naturally occurring zooplankton, juvenile pearl oysters are fed a dried artificial food, but this dried food is not considered a source for the copepod (e-mails from N. Iwasaki, 17 and 21 May 2008). For these reasons, the copepods are considered endemic to Zamami Island. The sample with P. schminkei sp. nov. was fixed in ca. 5\% neutralized formalin immediately after capture, transferred to $70 \%$ ethanol, and subsequently transferred into glycerol for slide preparation.

Pseudocyclops bilobatus Dawson, 1977: 6 female paratypes and 5 male paratypes from the Los Angeles County Museum (LACM CR 1975-586.2).

Pseudocyclops xiphophorus Wells, 1967: 1 female paratype and one male paratype from the Natural History Museum (BMNH 1967.8.4.2).

Pseudocyclops sp.: numerous females, males and juvenile copepodids from a culture maintained at the Shedd Aquarium in Chicago, IL (USNM 1123189). The origin of these copepods is not known but they may have been introduced into that aquarium in or on live corals from Fiji, or with live algae from the Caribbean. The aquarium system has been running for over 12 years and these Pseudocyclops were first observed about 5 years ago (e-mail from M. Schick, 14 February 2008). Because the origin of these animals in culture is not known, they are described but not named.

All specimens were observed either with phase contrast at $1,250 \times$ magnification used for preliminary observations and for the line drawings, or with bright field or differential 
interference contrast at magnifications of $375-1,875 \times$. Some specimens were dissected and stained in chlorazol black E. All drawings were prepared using a camera lucida on a Nikon HFX-DX compound microscope at a magnification of $1,000 \times$. Measurements were made with an ocular micrometer. Scale bars in illustrations are in micrometer.

Descriptive terms follow Ferrari (1995) with the exception of maxilla 1, maxilla 2 and maxilliped, which follow Ferrari and Ivanenko (2008). The term "complex" refers to two or more limb segments that are not separated by arthrodial membranes (Ferrari and Ivanenko 2001, Ferrari and Dahms 2007). A distal segment complex for rami of copepod swimming legs has been proposed by Ferrari and Benforado (1998); complete analyses are given in Ferrari and Dahms (2007). An epicuticular extension of a limb segment is a denticle. Somites are numbered according to their relative developmental age, following Hulsemann (1991). Total length, measured in lateral view and given as prosome length/urosome length $=$ total, includes caudal rami and rostrum but does not include the portion of the prosome that overlaps the urosome. The following abbreviations are used in the descriptions: Cph, cephalosome (cephalic somites $1-5$ plus thoracic somite 1 ); $\mathrm{Pr}$, prosome (cephalosome plus thoracic somites 2-6); Ur, urosome (thoracic somite 7 plus abdominal somites $1-4)$; $\mathrm{Pd} 1-\mathrm{Pd} 5,1$ st -5 th pedigerous somites [thoracic somites 2-6]; Th, thoracic somite; Abd, abdominal somite; A1, antennule; A2, antenna; Md, mandible; Mx1, maxillule; Mx2, maxilla; Mxp, maxilliped [1st thoracopod]; P1-P4, swimming legs 1-4 (thoracopods 2-5); P5, leg 5 (thoracopod 6); on A1, a segment with 1 seta and 1 aesthetasc on a segment is designated $1 \mathrm{~s}+1 \mathrm{ae}$; " 1 ?" indicates that a setal element was broken so that its identity on A1 could not be determined, and only the scar at the location of its attachment was counted.

Order Calanoida Sars, 1901

Superfamily Pseudocyclopoidea Andronov, 1974

Family Pseudocyclopidae Giesbrecht, 1893

Genus Pseudocyclops Brady, 1872

Species Pseudocyclops schminkei sp. nov.

Figures 1, 2, 3, 4, 5, 6, 7, 8, 9, 10, 11

Habitus: Female allotype, $0.40 / 0.15=0.55 \mathrm{~mm}$; 6 female paratypes, $\quad 0.43 / 0.13=0.56 \mathrm{~mm}, \quad 0.46 / 0.15=0.61, \quad 0.43 /$ $0.16=0.59, \quad 0.41 / 0.14=0.55, \quad 0.45 / 0.15=0.60, \quad 0.46 /$ $0.17=0.63$. Body (Fig. 1a, b) compact; Pr oval in dorsal view, 2.9 times as long as Ur. Cph ventrally with welldeveloped rostrum (Fig. 1b); Cph and Pd1 separate; thin arthrodial membrane between $\mathrm{Pd} 4$ and $\mathrm{Pd} 5$. Urosome (Fig. 2a, b) 4-segmented; genital double-somite, Abd 3, Abd 4 with pleated epicuticular fringe posteriorly; fringe of Abd 4 dorsally lobate (Fig. 1a). Genital double-somite with small point laterally toward anterior edge and ventral ridge posterior to paired, anteroventral oviducal openings; paired copulatory pores anterior to paired, tooth-like, ventral extensions of epicuticule (Fig. 2b); linear series of indentations from small point to copulatory pore on right side. Anal somite narrow, covered by posterior epicuticular fringe of Abd 4 (Fig. 2a; Table 1).

A1 (Fig. 3a): reaching beyond middle of Pd1; 17 articulating segments armed as follows: $1: 14 \mathrm{~s}+3 \mathrm{a} ; 2: 4 \mathrm{~s} ; 3: 2 \mathrm{~s}$; 4: $2 \mathrm{~s} ; 5: 2 \mathrm{~s} ; 6: 2 \mathrm{~s} ; 7: 2 \mathrm{~s} ; 8: 2 \mathrm{~s} ; 9: 2 \mathrm{~s} ; 10: 2 \mathrm{~s} ; 11: 2 \mathrm{~s} ; 12: 2 \mathrm{~s}$; 13: $2 \mathrm{~s} ; 14: 2 \mathrm{~s} ; 15: 4 \mathrm{~s} ; 16: 2 \mathrm{~s} ; 17: 6 \mathrm{~s}+1 \mathrm{a}$.

A2 (Fig. 3b): coxa unarmed; basis with distomedial seta. Endopod 3-segmented, proximal segment with 1 medial seta at midlength; middle segment with 5 setae along medial margin and 3 distomedial setae, and lateral and distal denticles; distal segment with 7 terminal setae, and lateral and medial denticles. Exopod appearing 6-segmented; proximal segment to 3rd segment with thin, distal arthrodial membrane and medial seta; 4th segment apparently a complex with 3 medial setae originating close together; 5th segment apparently a complex with 2 medial setae, at midlength and distally; terminal segment with 3 setae.

Md (Fig. 3c): coxa with hook-like attenuation, coxal gnathobase without seta and with 8 thick teeth; basis with 2 medial setae and medial denticles. Endopod 2-segmented, proximal segment with 4 distomedial setae, distal segment with 10 terminal setae. Exopod 4-segmented, distal segment with 3 setae, remaining segments with 1 medial seta each.

Mx1 (Fig. 4a, b): praecoxal endite extending distally with 5 thick and 3 thin ventral setae, 1 anterior seta and 4 posterior setae; coxal exite with 4 setae, coxal endite with 3 setae; basal exite with 1 seta, proximal endite well-developed with 3 setae, distal endite not extended ventrally with 4 setae; exopod lobate with 4 lateral and 7 terminal setae; endopod 2-segmented, proximal segment with groups of 5 mid-ventral and 4 distoventral setae; distal segment with 6 terminal setae.

Mx2 (Fig. 4c, d): praecoxal endite of syncoxa with 5 setae, coxal endite with 3 setae; proximal and distal basal endites with 3 setae each. Endopod 3-segmented; ventral lobe of proximal segment with 6 setae, middle segment with 1 posteroproximal seta and 2 distoventral setae, distal segment with 5 setae.

Mxp (Fig. 4e): syncoxa with 1, 1, 3 setae on proximal, middle and distal praecoxal endites, respectively, and 2 setae on coxal endite; proximal endite of basis pronounced, with 3 setae, distal endite with 2 setae; endopod 5-segmented with 2 medial, 2 medial, 2 medial, 2 (1 medial, 1 lateral), 4 (1 medial, 2 terminal, 1 lateral) setae.

P1-4 coxa with medial seta; rami 3-segmented (Figs. 5a, b, 6a, b), all with medial seta and lateral spine-like seta on the proximal and middle exopod segments; 1 medial seta on the proximal endopodal segment and 2 medial setae on the middle endopodal segment. Medial setae on exopod and all setae on endopod articulate. 
Fig. 1 Pseudocyclops schminkei sp. nov. female, allotype. a habitus, dorsal; b habitus, right lateral
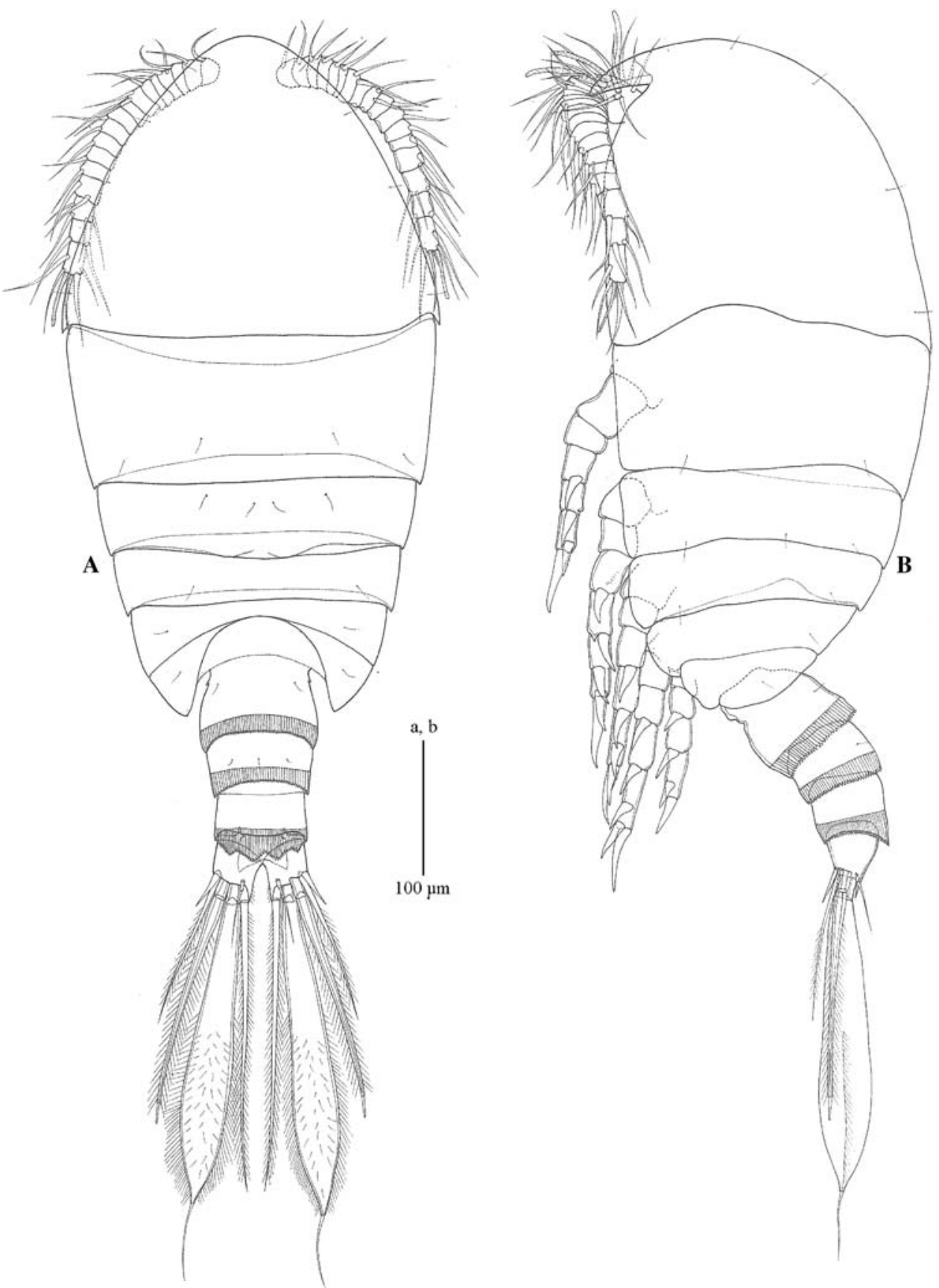

Basis of P1-2 unarmed; of P3 with lateral, spine-like seta; of P4 with lateral seta; basis of P3-4 attenuate distomedially. Distal exopodal complex of P1-2 with 2 lateral spine-like setae, of P3-4 with 3 lateral spine-like setae; distal complex of P1 with 4 medial setae, of P2-4 with 5 medial setae.

Distal endopodal complex of P1 with 1 lateral seta, 2 terminal setae and 3 medial setae; of P2-3 with 2 lateral seta, 2 terminal setae and 4 medial setae; of P4 with 2 lateral seta, 2 terminal setae and 3 medial setae.

P1 without denticles; P2-4 with denticles posteriorly on middle segment of exopod and endopod; P3-4 with denticles posteriorly on distal segment complex of exopod and endopod. P1 without pores on posterior surface; proximal endopodal segment of P3 with pore on posterior face; distal endopodal complex of P2-4 with pore and thickened integumental ridge internally on posterior face; distal exopodal complex of P3-4 with pore and thickened integumental ridge on posterior face.

P5 (Fig. 6c): intercoxal sclerite with complete row of denticles proximally and broken row of denticles distally; coxa with partial row of denticles laterally and complete row of denticles distally; basis attenuate distomedially with lateral seta. Proximal and middle exopodal segments without 

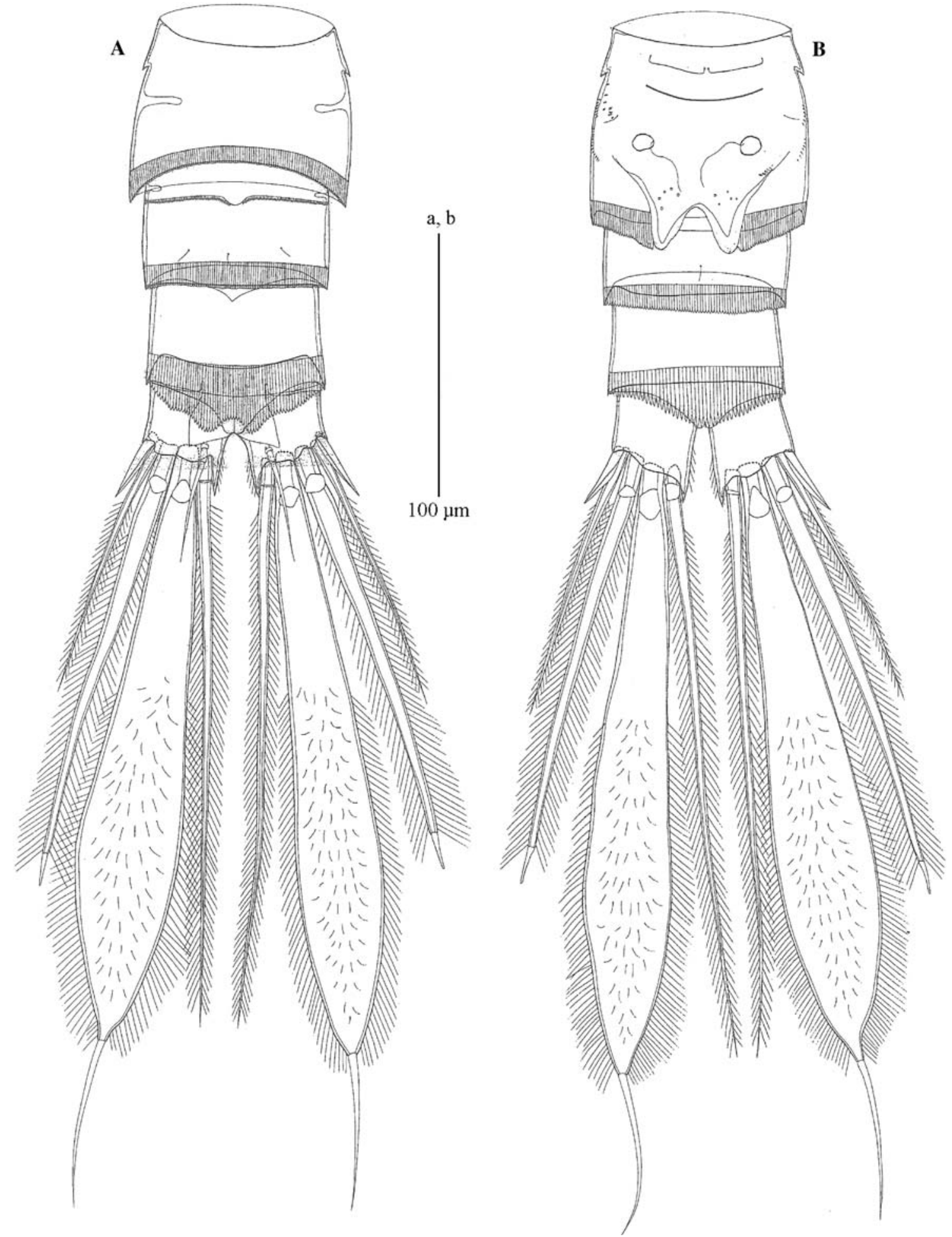

Fig. 2 Pseudocyclops schminkei sp. nov. female, allotype. a urosome, dorsal; b urosome, ventral

medial seta; middle segment with distomedial attenuation; distal complex with 2 lateral, 1 terminal and 1 distomedial spine-like setae, and a pore and thickened integumental ridge on posterior face. Proximal complex of endopod with arthrodial membrane anteriorly, opposite to a proximal row of denticles posteriorly, distally attenuate medially and laterally, without setae; distal segment attenuate distolaterally and slightly distomedially, with 2 terminal setae.

CR (Fig. 2a, b): posterodorsal margin extending beyond level of insertion of setae; medial attenuation; 1 dorsal, 1 
Fig. 3 Pseudocyclops schminkei sp. nov. female, allotype. a antenna 1 , b antenna 2, c mandible

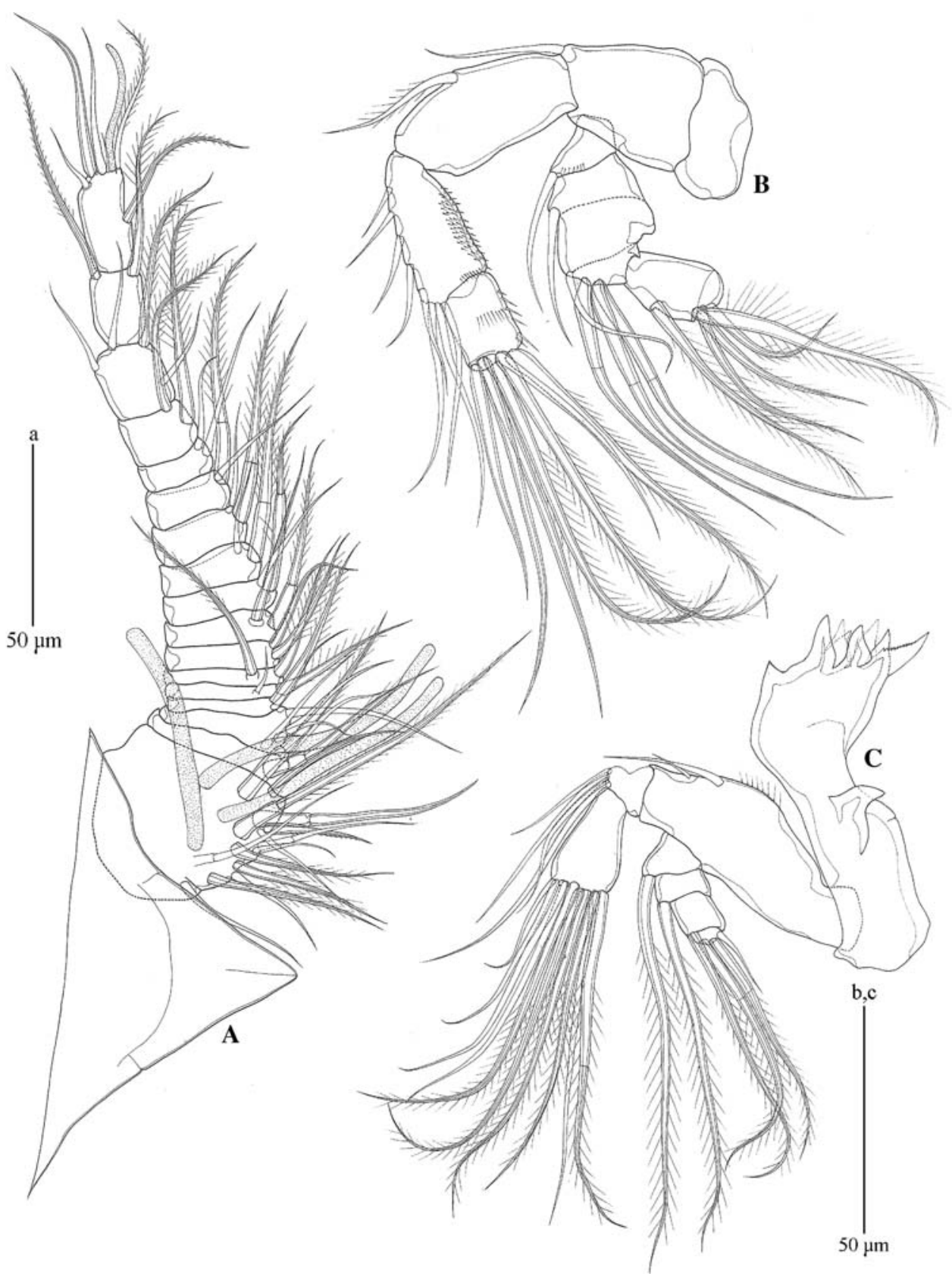

lateral seta and 4 terminal; lateral setae juxtaposed to 4 th terminal seta; 2nd terminal seta from medial broad proximally, thin distally (but see remarks for polymorphism); 3 largest setae with secondary articulation close to their insertion.

Habitus: Male holotype $0.43 / 0.16=0.59 \mathrm{~mm} ; 3$ male paratypes $\quad 0.43 / 0.14=0.57 \mathrm{~mm}, \quad 0.42 / 0.14=0.56 \mathrm{~mm}$, $0.42 / 0.17=0.59 \mathrm{~mm}$. Similar to female with the following exceptions. Pr (Fig. 7a, b) 3.0 times as long as Ur. Rostrum articulates at base. Ventrolateral margin of $\mathrm{Pd} 4$ extending to posterior edge of Th7. Genital opening represented by posteroventral slit on left side. Posterior border of Th7 and Abd 2-4 (Fig. 8a, b) with pleated epicuticular fringe; fringe of Th4 lobate dorsally; anal somite (Abd 1) narrow, hidden by posterior epicuticular fringe of adjacent somite.

A1: left similar to female (Fig. 9a); right also of 17 articulating segments (Fig. 9b); armature as follows: 1: $13 \mathrm{~s}+3 \mathrm{a} ; 2: 2 \mathrm{~s} ; 3: 2 \mathrm{~s} ; 4: 2 \mathrm{~s} ; 5: 2 \mathrm{~s} ; 6: 2 \mathrm{~s} ; 7: 2 \mathrm{~s} ; 8: 2 \mathrm{~s} ; 9: 2 \mathrm{~s}$; 10: $2 \mathrm{~s} ; 11: 2 \mathrm{~s} ; 12$ : $2 \mathrm{~s} ; 13: 2 \mathrm{~s} ; 14: 2 \mathrm{~s} ; 15: 4 \mathrm{~s} ; 16: 2 \mathrm{~s} ; 17$ : $6 s+1 \mathrm{a}$; proximal seta on articulating segments $12-14$ modified as a broad-based, spine-like seta closely appressed to segment; articulating segment 15 attenuate distally, tip reaching distal end of segment 16 .

A2, Mx1, Mx2 and Mxp similar to female.

Md (Fig. 9c): without hook-like attenuation on coxa. 
Fig. 4 Pseudocyclops schminkei sp. nov. female, allotype. a maxilla 1; b maxilla 1 , basis plus rami; c maxilla 2; d maxilla 2, endopod; e maxilliped, syncoxa

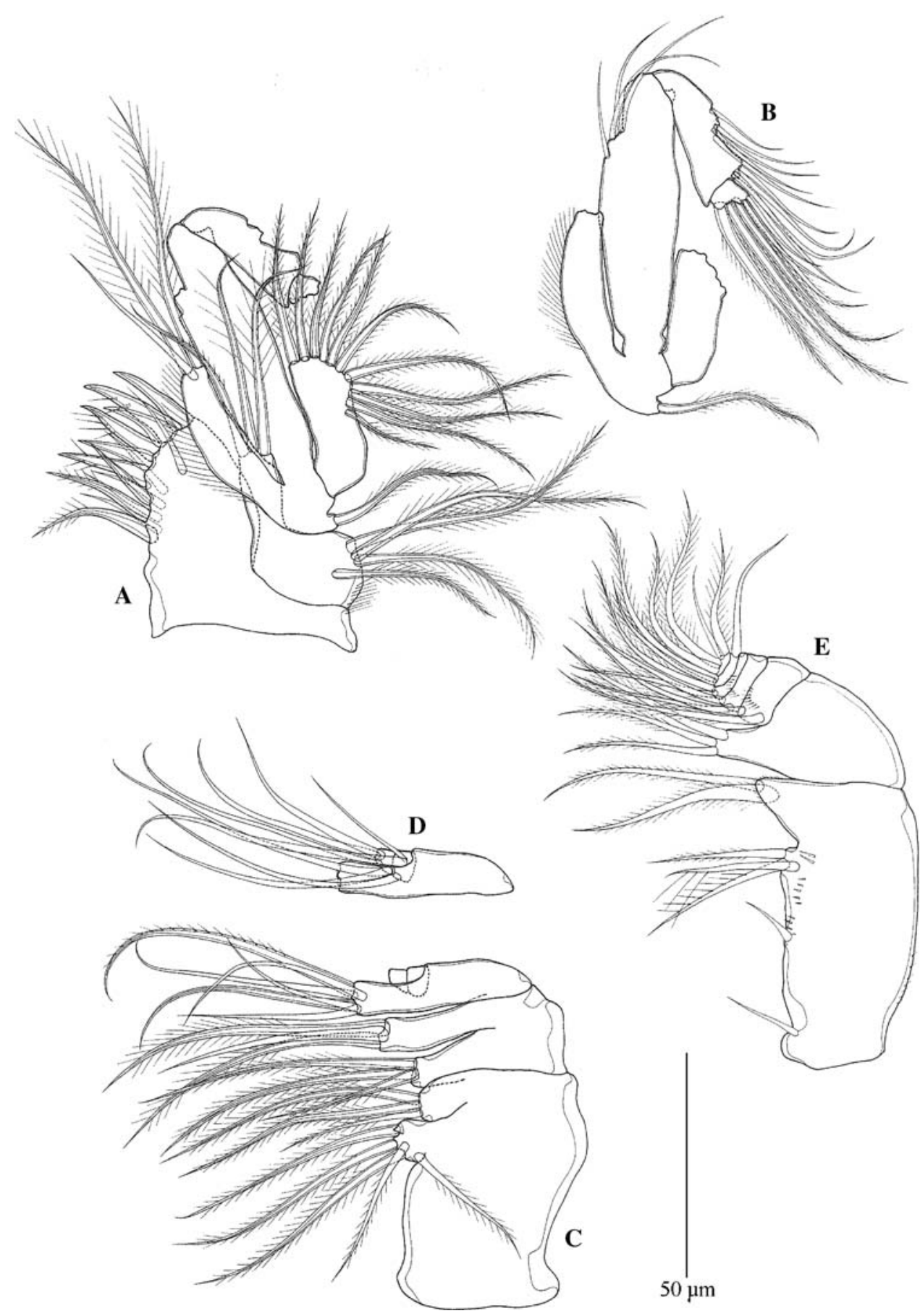

Swimming legs 1, 3, 4 similar to female but with denticles on basis (P1), or coxa, basis and rami (P3, 4).

Swimming leg 2: denticles on coxa, basis and rami. Tip of proximolateral seta on left distal exopodal complex projecting beyond imaginary line between tip of lateral seta on middle exopodal segment and tip of distolateral seta on distal exopodal complex (Fig. 10); tip of proximolateral seta on right distal exopodal complex not reaching that imaginary line.
P5 (Fig. 11a-d): intercoxal plate with ventral, beaklike lobe; right coxa fused to right basis; latter with lateral seta. Right exopod 2-segmented, proximal segment with lateral seta with epicuticular fringe on both sides; broad, blade-like medial seta with incomplete fringe on one side; distal segment thick, curved, spine-like attenuation with medial and lateral seta proximally. Right endopod 1-segmented, quadrate, without setae, with proximal and distal indentation. 
Fig. 5 Pseudocyclops schminkei sp. nov. female, allotype. a right swimming leg 1 , b right swimming leg 2

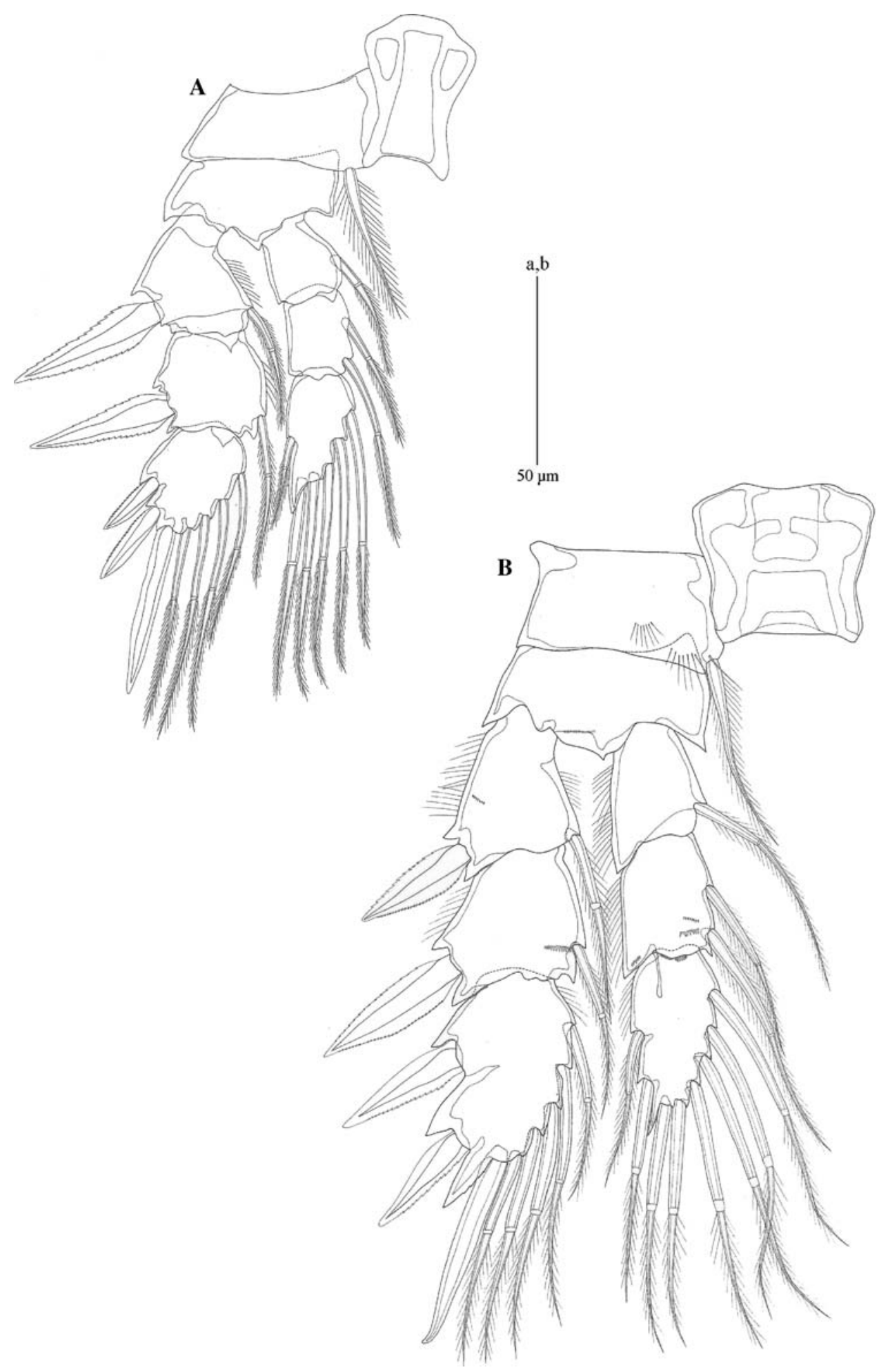

Left coxa fused to left basis; latter with lateral seta; basis with broad attenuation narrowing and folded on itself forming grooved, pointed tip. Left exopod apparently 2 -segmented, proximal segment with lateral seta with epicuticular fringe on one side, and medial attenuation with denticles; distal segment with broad, quadrate, proximolat- eral lobe with medial denticles, followed by small middle lobe with lateral denticles, and broad, distal lobe flexed $90^{\circ}$; with 2 pointed lobes apically; 1 small seta proximal to quadrate lobe and 1 small seta proximal to flexed lobe. Left endopod 1-segmented, rounded, without setae, with distal, tongue-like lobe. 
Fig. 6 Pseudocyclops schminkei sp. nov. female, allotype. a right swimming leg 3 , b right swimming leg 4; c right leg 5

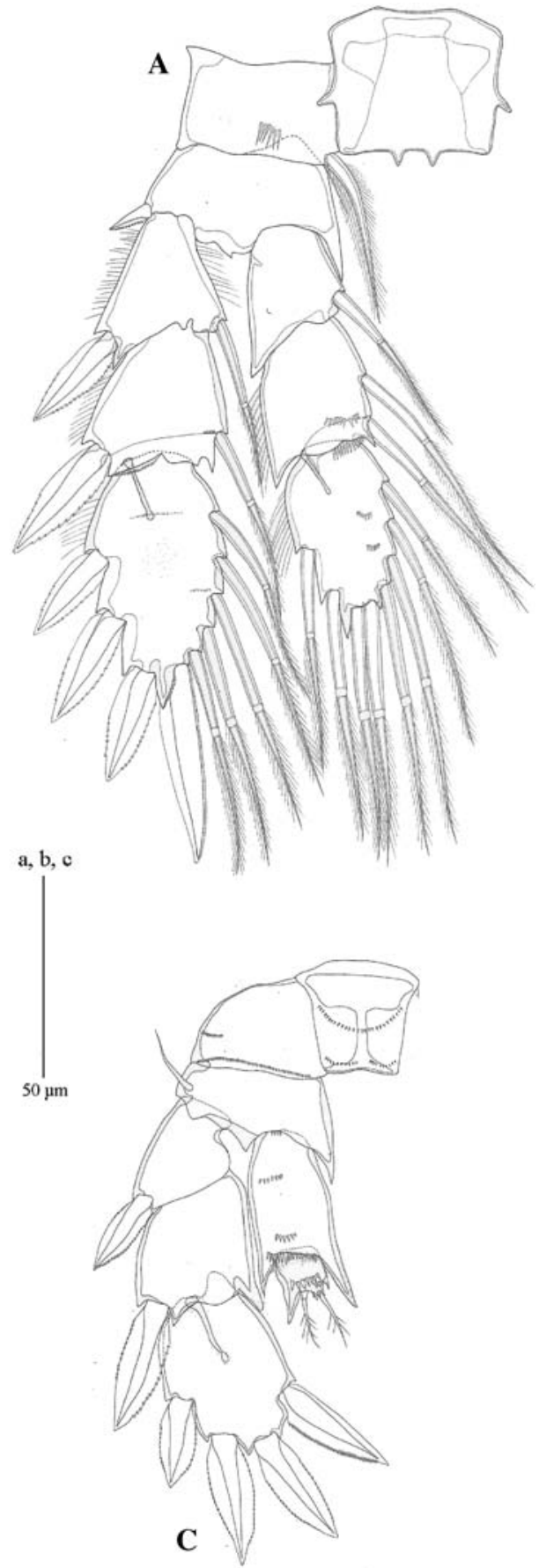

CR (Fig. 8a, b): 2nd terminal seta thick but tapering smoothly distally.

Etymology This species honors the eminent carcinologist Prof. Dr. Horst-Kurt Schminke at the University of Oldenburg, Germany.

Distribution Pseudocyclops schminkei sp. nov. is known only from its type locality, Zamami Island, Okinawa, Japan.

Remarks Thirty-six species belonging to Pseudocyclops have been described, all from tropical or temperate shallow waters. Descriptions of many of these species are incomplete. Ohtsuka et al. (1999) established four species groups for 8 of the 35 species: the lepidotus-species group (P. lepidotus, P. ornaticauda Ohtsuka, Fosshagen and Putchakarn, 1999); the kulai-species group ( $P$. kulai Othman and Greenwood, 1989, P. ensiger Ohtsuka, Fosshagen and Putchakarn, 1999); and the crassiremis-species group (P. crassiremis, P. bahamensis Fosshagen, 1968, P. oliveri Fosshagen 1968, P. minutus Ohtsuka, Fosshagen and Putchakarn, 1999); and the magnus-species group (P. magnus, 
Fig. 7 Pseudocyclops schminkei sp. nov. male, holotype. a habitus, dorsal. b Habitus, left lateral
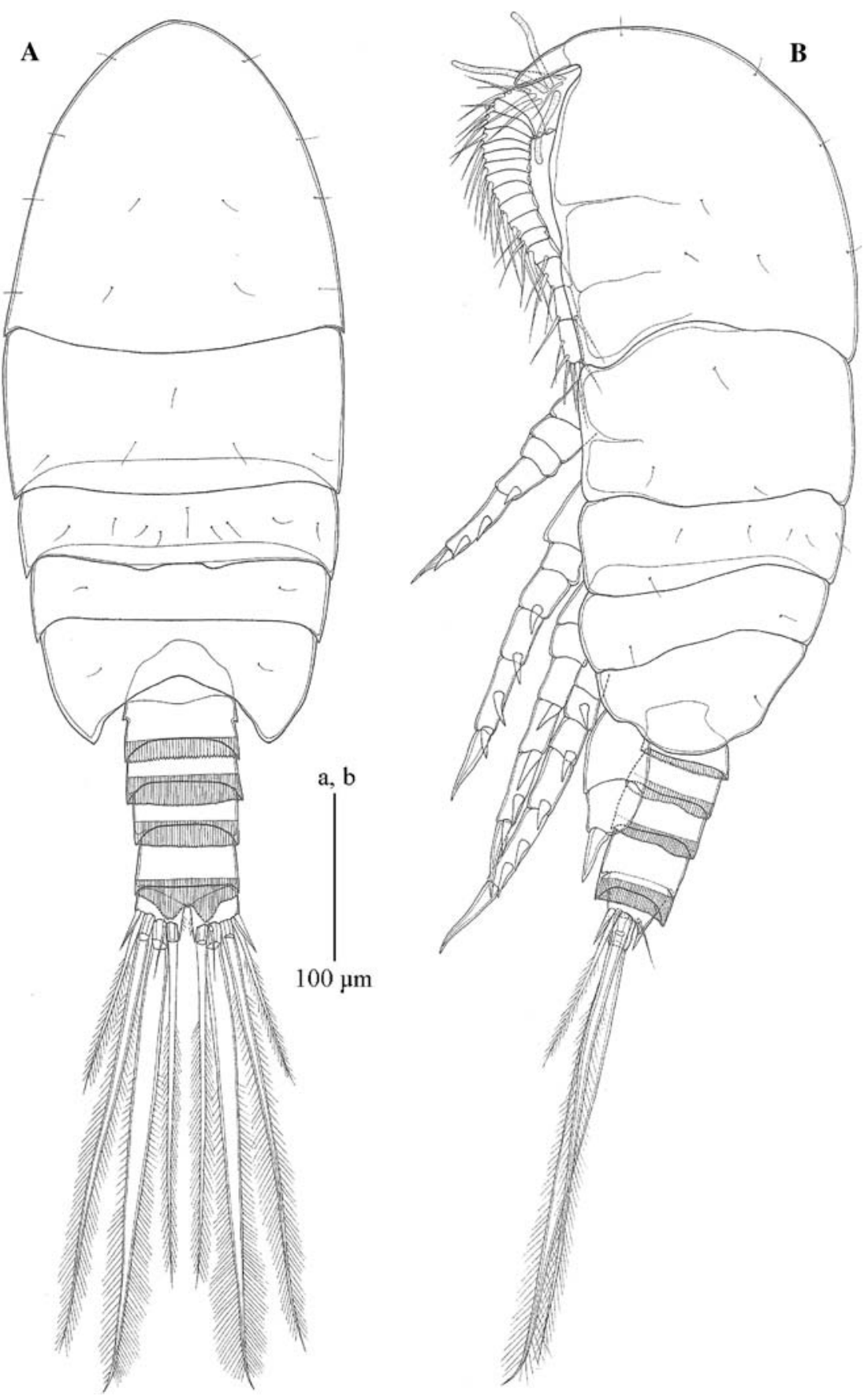

P. latens, P.xiphophorus, P. bilobatus). No other species group has been proposed subsequently.

Pseudocyclops schminkei sp. nov. belongs to the mag$n u s$-species group, which includes $P$. magnus from Bermuda (northwestern Atlantic Ocean), P. latens from Ismailia on the west bank of the Suez Canal (northwestern Indian Ocean), P. xiphophorus from Mozambique (western Indian Ocean), P. bilobatus from Southern California (northeastern Pacific Ocean). Pseudocyclops mag$n u s$ and $P$. latens are known only from females and for this reason separating either from similar species remains problematical. Pseudocyclops magnus and P. xiphophorus have been redescribed, respectively, by Yeatman (1975) and by Zagami et al. (2005) and Brugnano et al. (2009).

Species of the magnus-species group share the absence of medial setae on the exopodal segments of female leg 5 , the absence of medial seta but with acute attenuations distolaterally and distomedially on the middle endopodal segment of female leg 5, a distal endopodal segment with 1-2 setae and an acute process terminally, female genital double somite with a pair of posteriorly directed processes [here 
Fig. 8 Pseudocyclops schminkei sp. nov male, holotype. a urosome in dorsal view, $\mathbf{b}$ urosome in ventral view

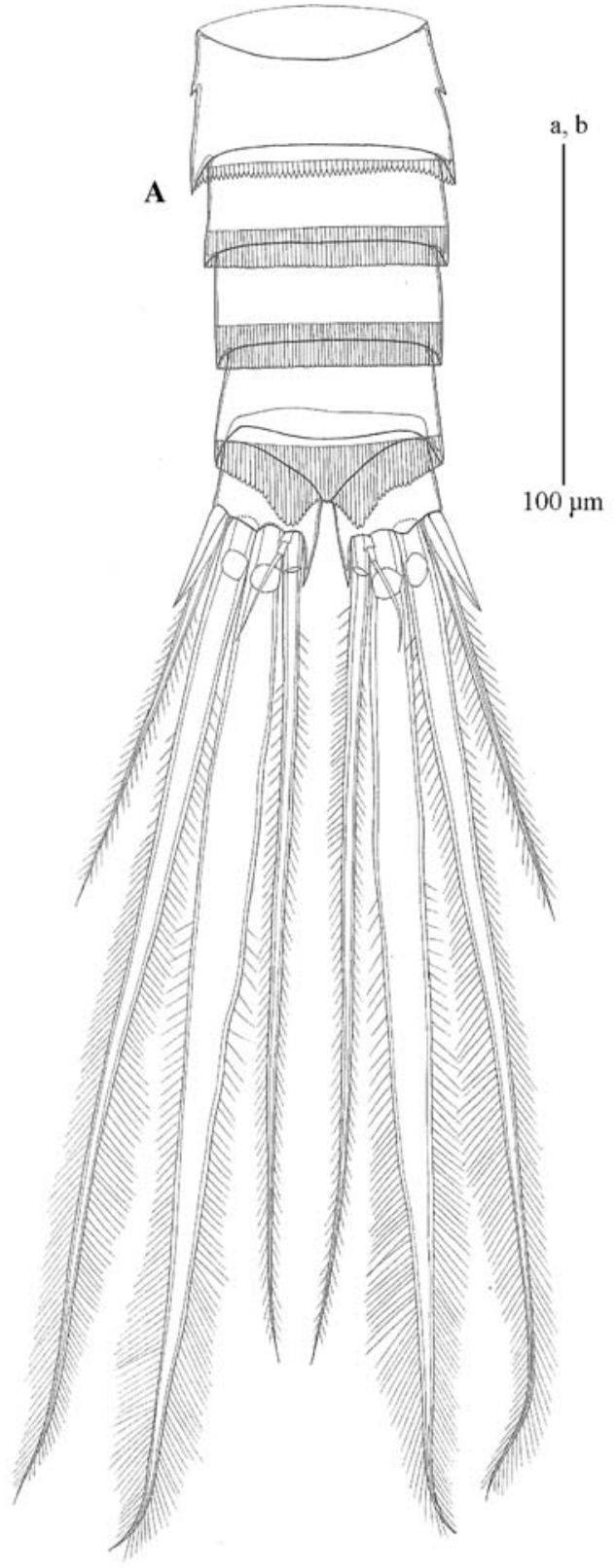

flap-like extensions of the epicuticle] (for $P$. magnus, $P$. xiphophorus, and $P$. latens); a spatulate seta in the 2nd from medial position of female caudal ramus (here spatulate proximally but thinner distally) (for P. magnus, P. xiphophorus, $P$. bilobatus).

Ohtsuka et al. (1999) hypothesized that the crassiremis-species group (P. crassiremis, P. bahamensis, $P$. oliveri, $P$. minutus) and the magnus-species group are derived groups within the genus, sharing: fused 4th and 5 th pedigers; an antennule of 16 or 17 articulating segments; male rostrum articulating at base; absence of medial seta on basis of swimming leg 1; 1- or 2-segmented endopod of female leg 5; left endopod of male leg 5 without setae. Pseudocyclops schminkei sp. nov. also shares these character states. Pseudocyclops costanzoi Baviera, Crescenti and Zagami, 2007, one of two species described since Ohtsuka et al. (1999), appears to belong to this clade but does not appear to belong to the magnus-species group; Pseudocyclops giussanii Zagami, Brugnano, Costanzo, 2008 is quite different from all other species of the genus.

Pseudocyclops schminkei sp. nov. from Zamami Island, Okinawa, can be separated from the northwestern Atlantic $P$. magnus originally described from Bermuda from female only with body length of $1.1 \mathrm{~mm}$ (Esterly 1911). Subsequently the species was reported from 
Fig. 9 Pseudocyclops

schminkei sp. nov. male, holotype. a left first antenna in anterior view, $\mathbf{b}$ right first antenna in anterior view, c mandible

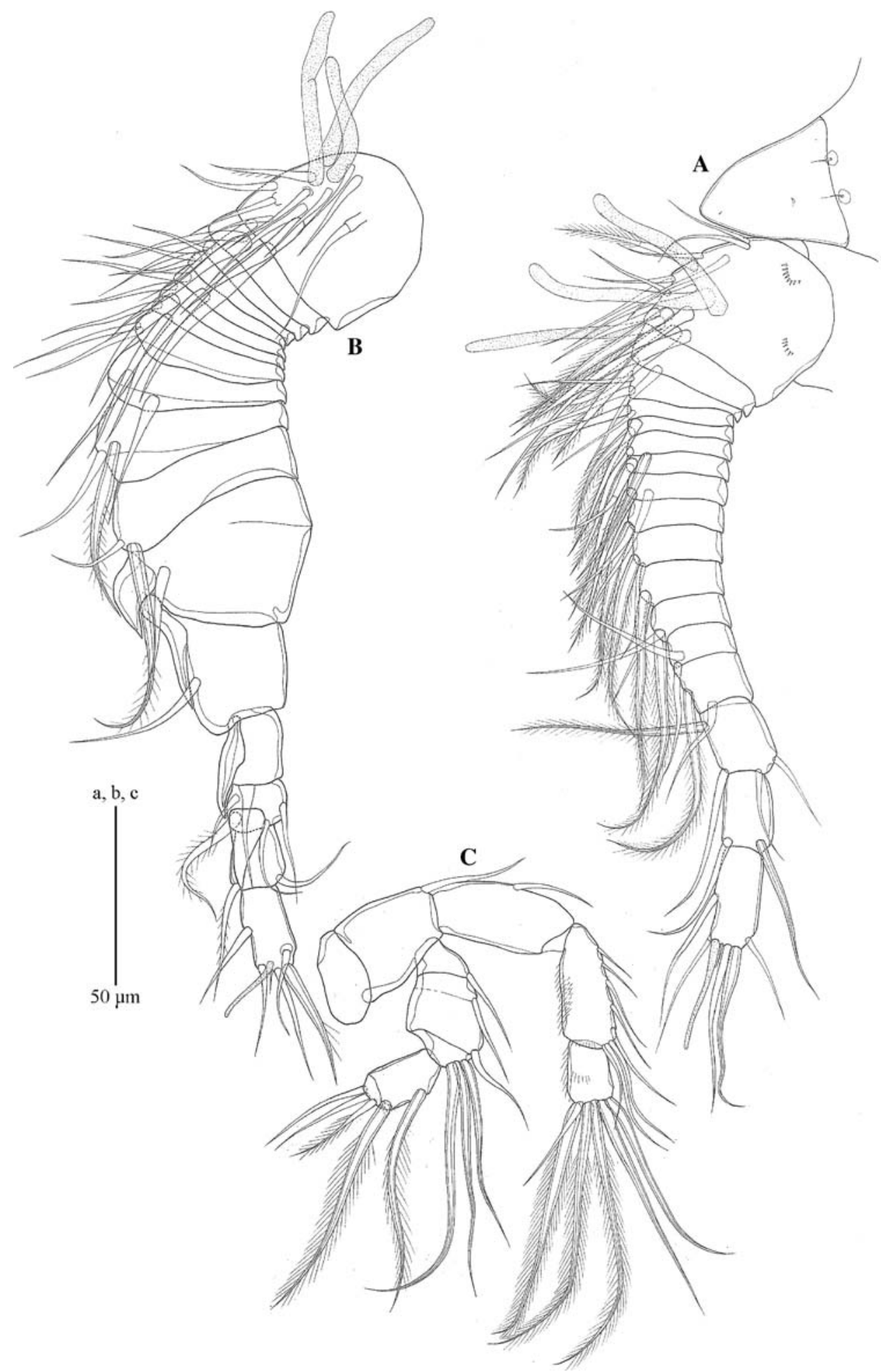

Barbados (Yeatman 1975) females were much smaller, $0.60-0.68 \mathrm{~mm}$, males were $0.59-0.62 \mathrm{~mm}$ [females of P. schminkei sp. nov. $0.55-0.63 \mathrm{~mm}$, males $0.57-0.59 \mathrm{~mm}$ ]. Females of $P$. schminkei sp. nov. differ from the female of $P$. latens in their distributions; $P$. latens is known only from the Red Sea, northwestern Indian Ocean (Gurney 1927).

Pseudocyclops schminkei sp. nov., length of female $0.55-0.63 \mathrm{~mm}$, of males $0.56-0.59 \mathrm{~mm}$, is smaller than P. xiphophorus females from Mozambique 0.719-0.759 mm 


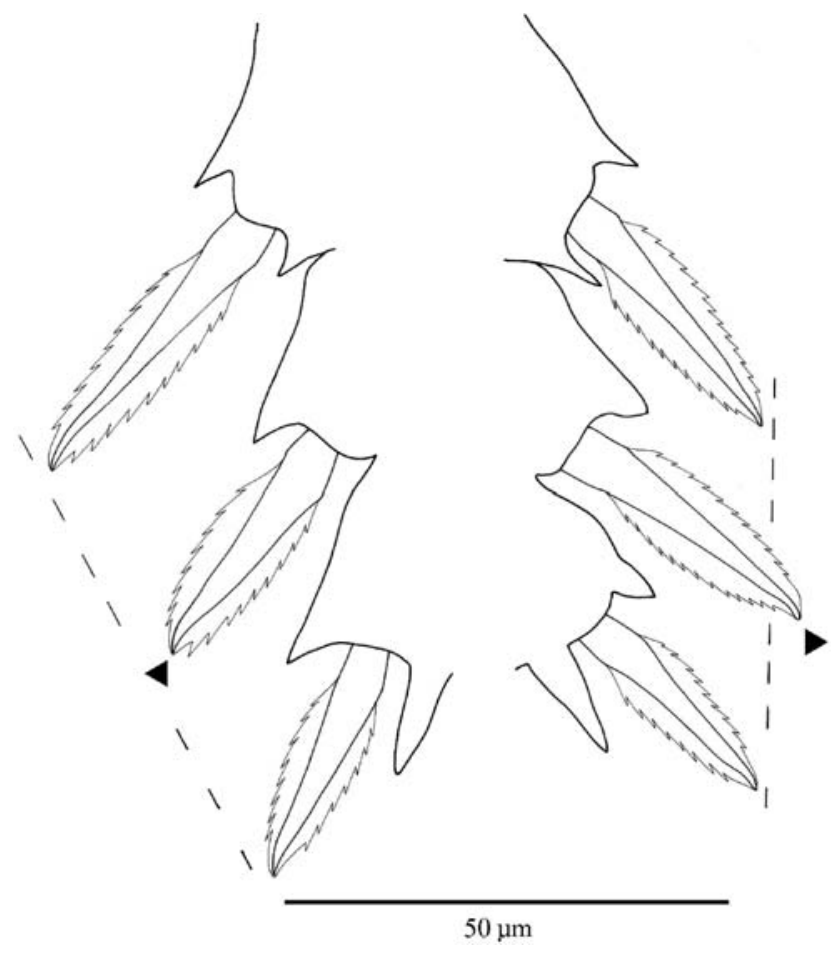

Fig. 10 Pseudocyclops schminkei sp. nov. male, holotype. a swimming leg 2; lateral margin of left and right middle and distal exopod showing slight difference in length of proximal (middle) spine-like seta (arrowhead) on distal complex; imaginary broken lines for reference

(0.67 mm paratype), males $0.680-0.733 \mathrm{~mm}(0.65 \mathrm{~mm}$ paratype); females from Lake Faro $0.624-0.671 \mathrm{~mm}$, males $0.624-0.656 \mathrm{~mm}$. The proximolateral lobe on the left exopod of male leg 5 of $P$. xiphophorus does not extend distally as far as the corresponding lobe of P. schminkei sp. nov. (compare Fig. 12d and Fig. 11d), and the margin of the middle lobe is straight (curved for P. schminkei sp. nov.); the shape of the distal lobe and terminal lobes also varies (compare Fig. 12d and Fig. 11d). The epicuticular fringe of the lateral seta on the middle exopodal segment of male right swimming leg 2 is asymmetrical and the proximal lateral seta of the distal segment is curved posteriorly (Fig. 12e, f) (these setae are symmetrical and straight on $P$. schminkei sp. nov.).

Pseudocyclops bilobatus differs significantly from P. schminkei sp. nov. The mean length of 49 females of P. bilobatus is $0.73 \mathrm{~mm}, 0.65-0.70 \mathrm{~mm}$ here for 6 paratypes, of 48 males $0.65 \mathrm{~mm}, 0.59-0.61 \mathrm{~mm}$ here for 5 paratypes (differences between Dawson's lengths and those given here for paratypes may be the result of Dawson including in his length of prosome that portion of the prosome that overlaps the urosome) [length range of females of $P$. schminkei sp. nov. $0.55-0.63 \mathrm{~mm}$, length range of males $0.57-0.59 \mathrm{~mm}$ ]. Terminal setae on exopod of female leg 5 are relatively longer on P. bilobatus so that lateral seta appears much shorter than adjacent terminal seta (see Dawson 1977: Fig. 18) [relatively shorter (Fig. 6c) for P. schminkei sp. nov.]; the arthrodial membrane between proximal and middle endopodal segments of female leg 5 arthrodial membrane on P. bilobatus is complete anteriorly but without a row of denticles posteriorly (not shown by Dawson 1977: Fig. 18) [restricted anteriorly with a proximal row of denticles on the posterior face (Fig. 6c) of P. schminkei sp. nov.]; terminal endopodal segment of female leg 5 of $P$. bilobatus relatively long so that its lateral attenuation extends beyond tip of the medial attenuation of the middle segment (see Dawson 1977: Fig. 18) [terminal endopodal segment of $P$. schminkei sp. nov. relatively short so that its lateral attenuation does not extend past the tip of the medial attenuation of the middle segment (Fig. 6c)]; the paired, ventral extensions of epicuticule of the genital double somite round and more widely separated [of P. schminkei sp. nov. tooth-like, and close to one another]; the attenuation of articulating segment 15 of male antenna 1 pointed ventrally (Fig. 13e) [pointed distally (Fig. 9b) on P. schminkei sp. nov.]. There are numerous differences in male leg, compare (Fig. 13a-d) for P. bilobatus with (Fig. 11a-d) for P. schminkei sp. nov., and there is no gender-limited asymmetry for male right swimming leg 2 of $P$. bilobatus.

\section{Discussion}

The 2nd terminal seta from medial seta on the caudal ramus of females of $P$. schminkei sp. nov. is polymorphic; as reported here, it is usually broad proximally and thin distally on most females, but on a few specimens it may be thick proximally but tapering smoothly distally, like the males. A similar polymorphism also has been reported for $P$. obtusatus asymmetrica by Ummerkutty 1968 and for P. xiphophorus by Brugnano et al. (2009).

Vervoort (1964) initially described a male genderlimited asymmetry of the exopod of swimming leg 2 of Pseudocyclops, viz. the distolateral seta on the distal exopodal complex of males of $P$. pacificus. Subsequently, Brugnano et al. (2009) described the genderlimited asymmetry of male right swimming leg 2 of $P$. xiphophorus as a gender-limited dimorphism. In this study, the subtle difference in the proximolateral seta of the distal exopodal complex of swimming leg 2 on males of $P$. schminkei sp. nov. was suggested by the more pronounced morphological asymmetry of the Pseudocyclops sp. from the Shedd Aquarium. The Shedd Aquarium in Chicago, IL, USA maintains a population 


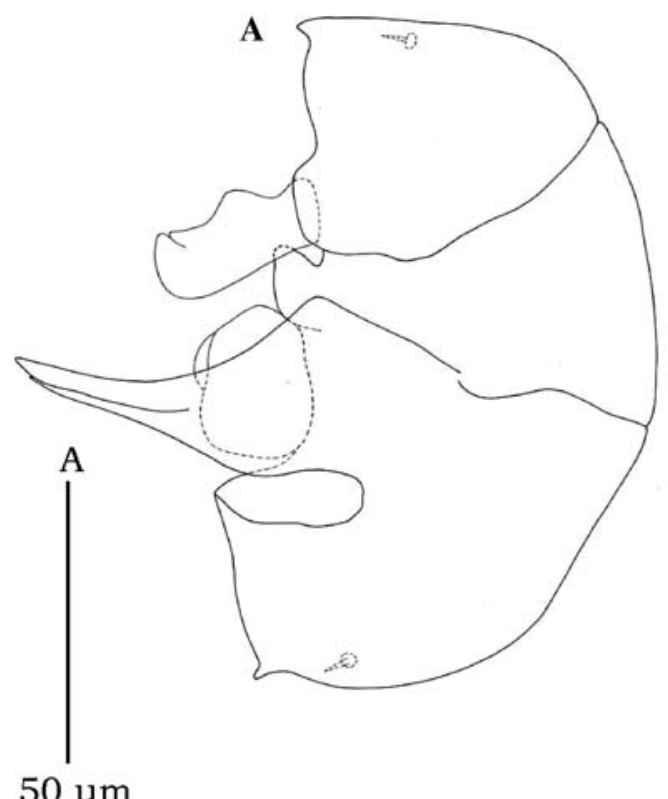

$50 \mu \mathrm{m}$

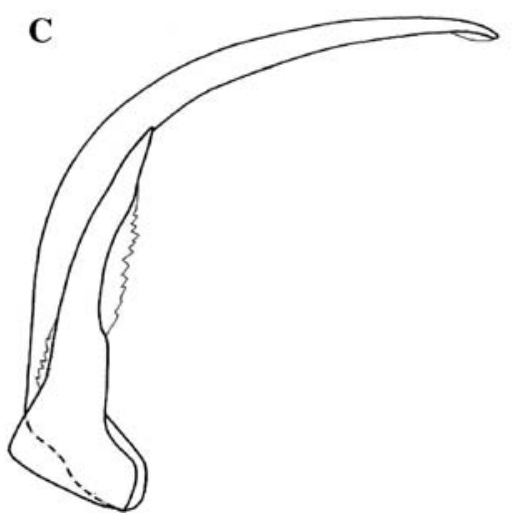

B

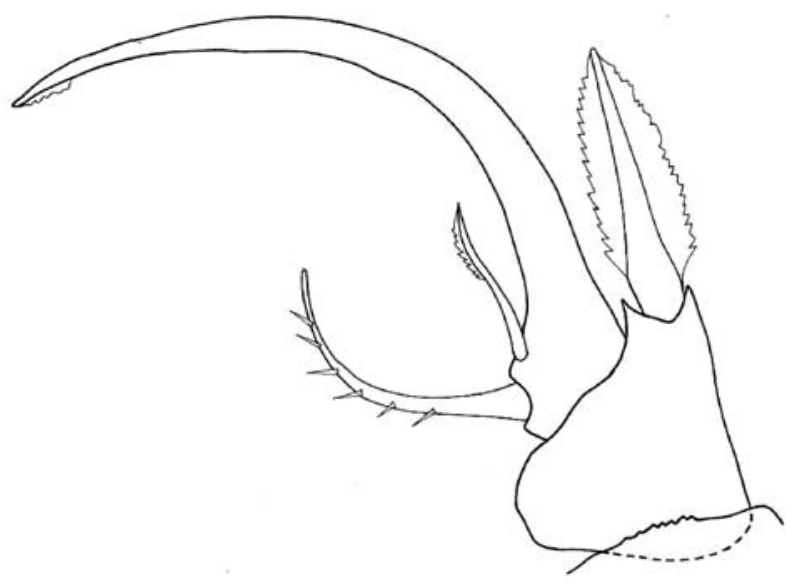

B, C, D

$100 \mu \mathrm{m}$

D

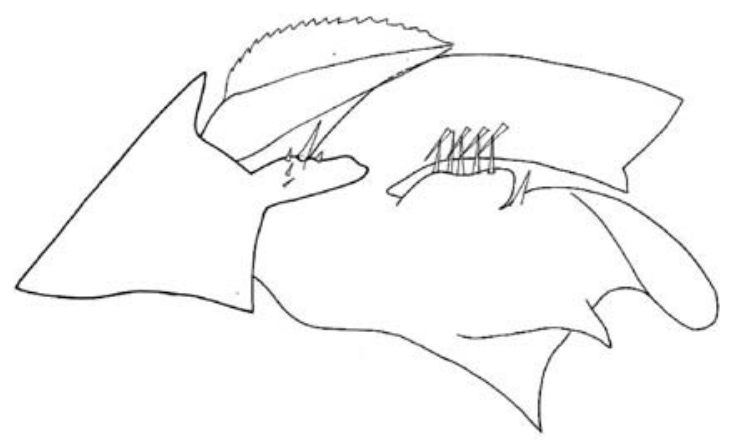

Fig. 11 Pseudocyclops schminkei sp. nov. male, holotype; leg 5. a protopod and endopods, anterior; b right exopod, anterior; c right exopod, medial seta of proximal segment and distal segment, posterior; $\mathbf{d}$ left exopod, anterior

Table 1 Setal formula of four swimming legs and leg 5 are as follows

$n f$ segment not formed, amn arthrodial membrane not formed

\begin{tabular}{|c|c|c|}
\hline P1: coxa $0-1$ basis $0-0$ & $\exp 1-1,1-1,2-1-4$ & enp $0-1,0-2,1-2-3$ \\
\hline P2: coxa $0-1$ basis $0-0$ & $\exp 1-1,1-1,2-1-5$ & enp $0-1,0-2,2-2-4$ \\
\hline P3: coxa $0-1$ basis $1-0$ & $\exp 1-1,1-1,3-1-5$ & enp $0-1,0-2,2-2-4$ \\
\hline P4: coxa $0-1$ basis $0-0$ & $\exp 1-1,1-1,3-1-5$ & enp $0-1,0-2,2-2-3$ \\
\hline $\mathrm{P} 5$ : coxa $0-0$ basis $1-0$ & $\exp 1-0,1-0,2-1-1$ & enp $0-0$, amn, $0-2-0$ \\
\hline P5 & $\exp 1-0, \mathrm{nf}, 0-0-0$ & enp nf, nf, $0-0-0$ \\
\hline P5 3 r: coxa $0-0$ basis $0-1$ & $\exp 1-1, \mathrm{nf}, 1-0-1$ & enp nf, nf, $0-0-0$ \\
\hline
\end{tabular}

of Pseudocyclops sp. as food for larval Amphiprion spp. and juvenile Hippocampus spp. The seawater system from which the specimens here were isolated has hosted corals and sea grass from the Caribbean Sea and from many tropical localities in the Pacific Ocean, so the provenance of the species is not known. This population is briefly described because of its more pronounced gender-limited asymmetry of male swimming leg 2. Pseudocyclops sp. from the Shedd Aquarium is similar to $P$. schminkei sp. nov. with a length range for females of 
Fig. 12 Pseudocyclops xiphophorus Wells, 1967, male paratype; leg 5. a protopod and endopods, anterior; b right exopod, anterior; c right exopod, medial seta of proximal segment, posterior; d left exopod, anterior. Right swimming leg 2 , e middle segment and distal complex of exopod, anterior; f lateral seta of middle segment and proximolateral seta of distal complex of exopod, lateral
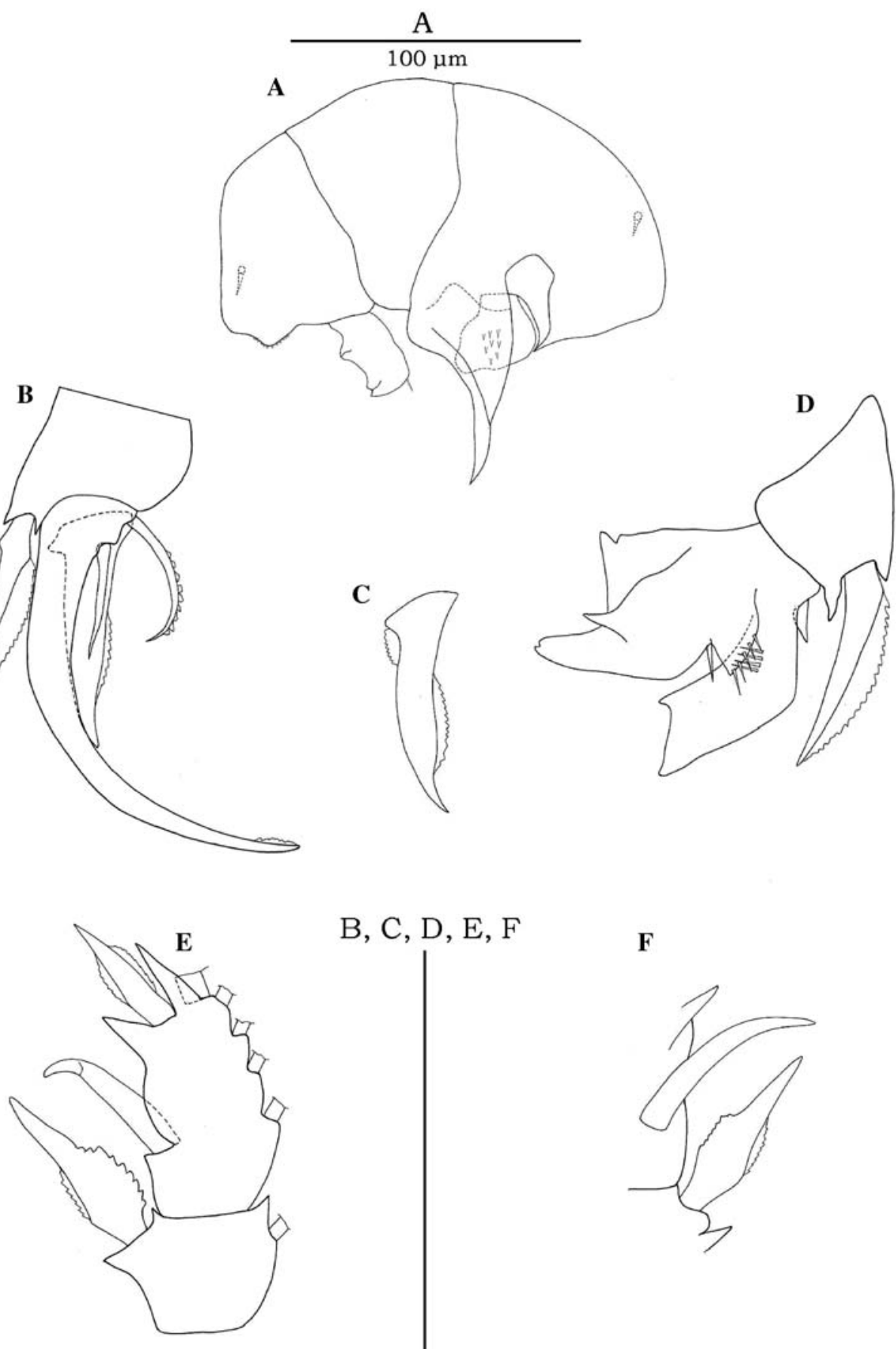

B, C, D, E, F

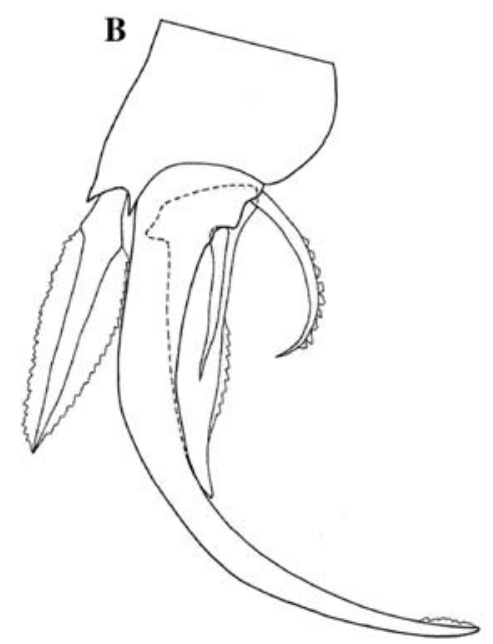

F

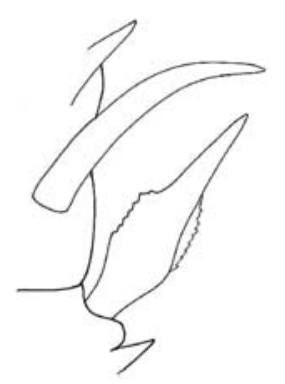

$0.67-0.69 \mathrm{~mm}$ and for males of $0.67-0.69 \mathrm{~mm}$. The distal attenuation of articulating segment 15 on right antenna 1 of males reaches beyond segment 16 as it does for $P$. schminkei sp. nov. The intercoxal plate of male leg 5 has a simple, ventral lobe (Fig. 14a), and the distal segment of the right exopod is thick, relative to its length (Fig. 14b, c). The proximolateral lobe of the distal segment of left exopod is not simply quadrate, and the distal part of the limb is broader (Fig. 14d). The lateral seta on middle exopodal segment of the right swimming leg 2 of males is irregularly swollen (Fig. 14e, f); the proximal seta on distal segment is curved posteriorly, and the lateral margin between the proximal and distal lateral seta is swollen (Fig. 14e, g). 
Fig. 13 Pseudocyclops bilobatus Dawson, 1977, male paratype; leg 5. a protopod and endopods, anterior; $\mathbf{b}$ right exopod, anterior; c right exopod, posterior; d left exopod, anterior; e terminal two segments of left antenna 1
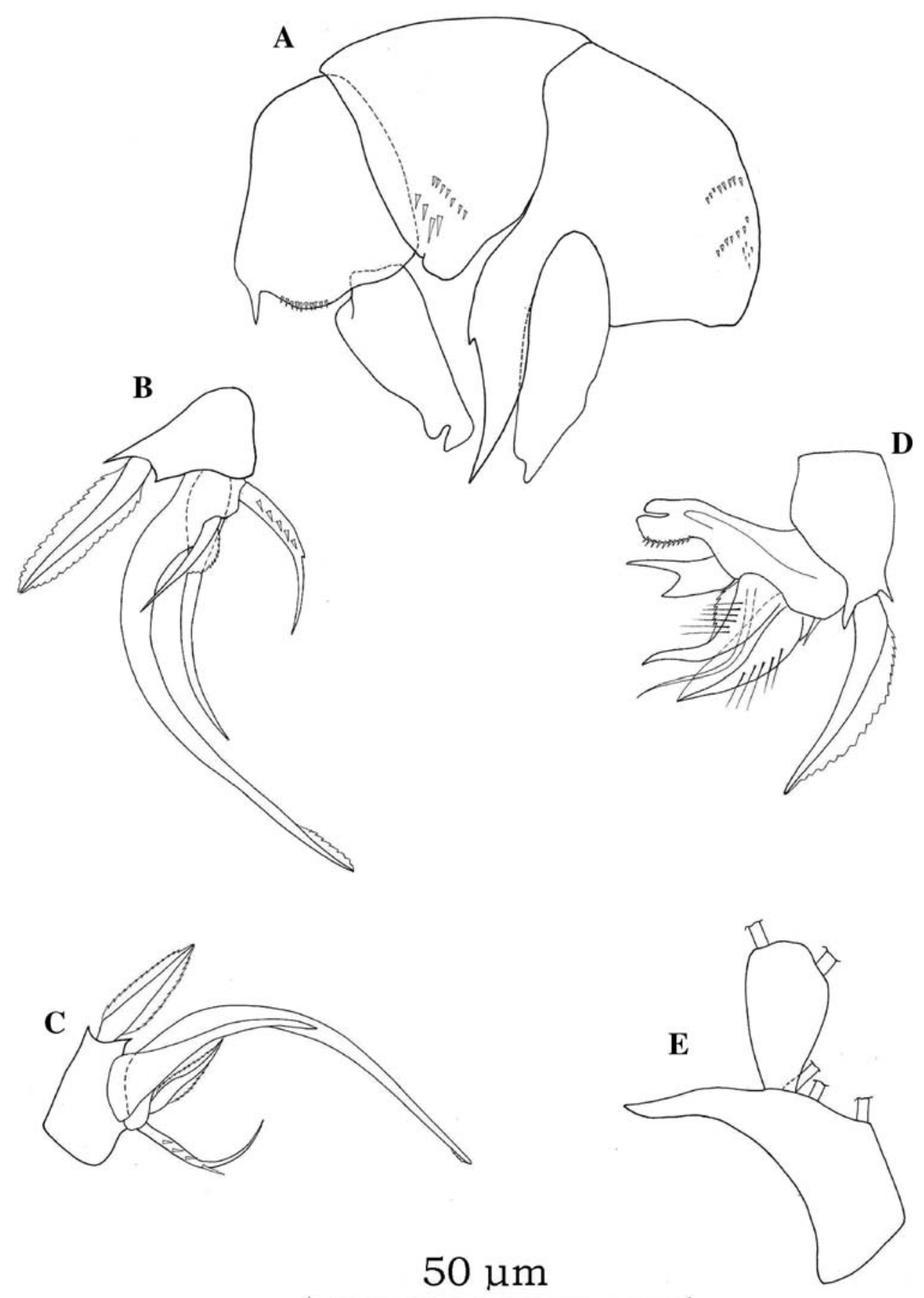

$50 \mu \mathrm{m}$

Brugnano et al. (2009) have proposed that the genderlimited asymmetry for male right swimming leg 2 of $P$. xiphophorus in Lake Faro, Sicily, is a gender-limited dimorphism, although the protocol described for different morphs used in the paternal identity experiments was not exclusive. It also appears that $P$. xiphophorus males from Lake Faro can be divided into two groups based on the morphology of the attenuation of the left basis (Brugnano et al. 2009: Fig. 9a, d). We have not found evidence for a gender-limited dimorphism among four male specimens of $P$. schminkei sp. nov., admittedly a small sample size, or among 25 male specimens of Pseudocyclops sp. from the Shedd Aquarium. We believe that this asymmetry is species specific and exhaustive. 


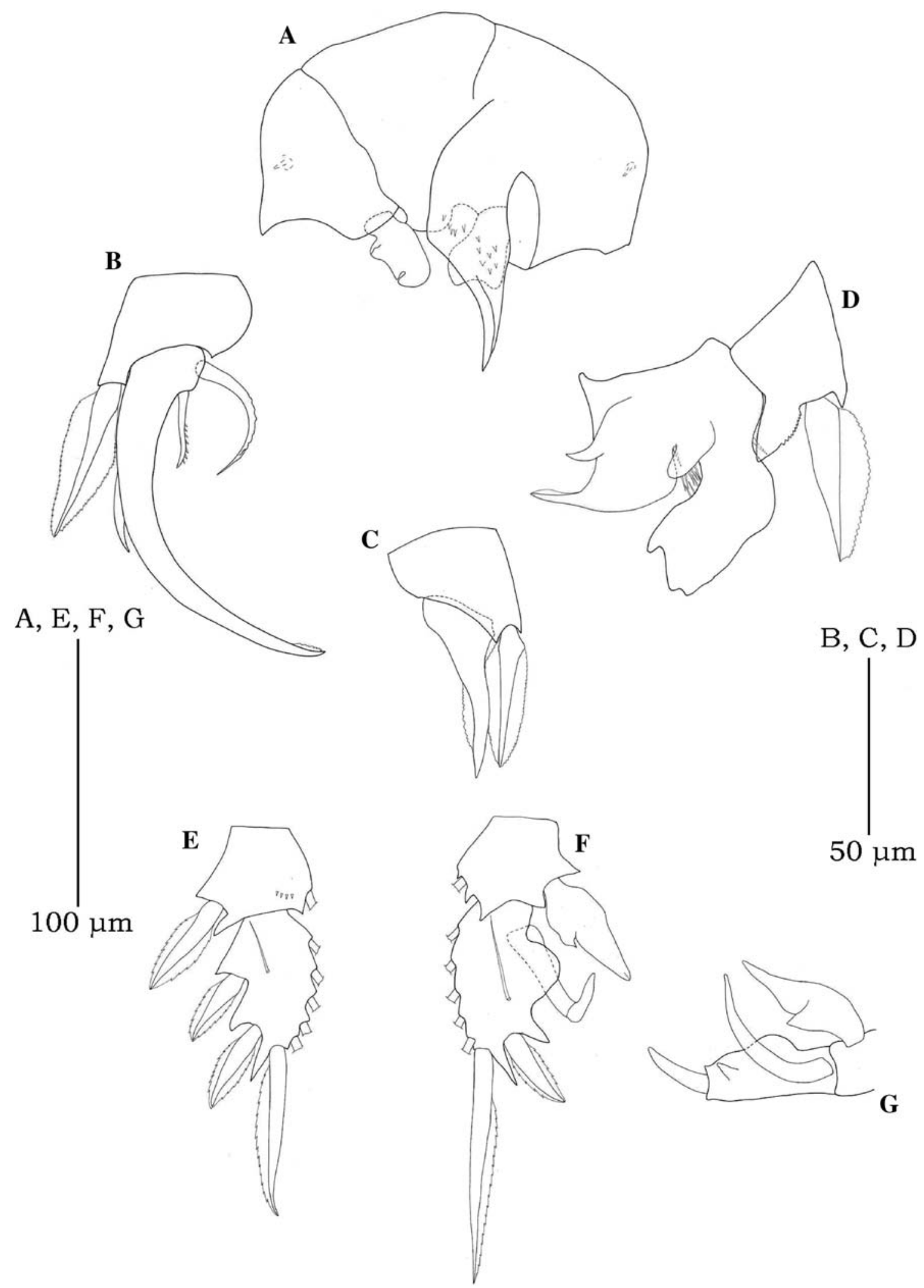

Fig. 14 Pseudocyclops sp. male from Shedd Aquarium population. Leg 5. a protopod and endopods, anterior; $\mathbf{b}$ right exopod, anterior; c right exopod, proximal segment, posterior; d left exopod, anterior. Swimming leg 2, e middle segment and distal complex of left exopod, anterior; f middle segment and distal complex of right exopod, anterior; $\mathbf{g}$ lateral seta of middle segment and proximo- and distolateral seta of distal complex of right exopod, lateral 
Acknowledgments Mr. Yoji Ichimura and Mr. Hirofumi Kurosaki of Kerama Pearl Ltd, and Dr. Shuichi Sakamoto of Oriental Yeast Co., Ltd collected the specimens of Pseudocyclops schminkei sp. nov.; these were made available to us by Dr. Nozomu Iwasaki of Kochi University. The authors are grateful to George Davis and Joel Martin of the Los Angeles County Museum for paratypes of P. bilobatus, and to Miranda Lowe and Geoffrey Boxshall of the Natural History Museum, London for paratypes of $P$. xiphophorus. Mark Schick of the Shedd Aquarium in Chicago donated specimens of Pseudocyclops sp. from an aquarium there. Dr. Chang-tai Shih of NTOU, Keelung kindly provided suggestions, encouragement and copies of publications.

\section{References}

Andronov VN (1986) Pridonnye Copepoda raiona Kap-Blan (Islamskaya respublikka Mavritaniya). 3. Semestvo Pseudocyclopidae. [Bottom Copepoda in the area of Cape Blanc (Islamic Republic of Mauretania). 3. The family Pseudocyclopidae]. Zoologicheskii Zhurnal 65::456-462 (Russian, English summary)

Andronov VN (2007) Novye rod i vid veslonogikh rakov (Crustacea, Calanoida) iz tsentral'no-vostochnoi atlantiki i problemy makrotaksonomii nadsemeistv Pseudocyclopoidea i Epacteriscoidea. [New genus and species of copepods (Crustacea, Calanoida) from the central-eastern Atlantic and problems of classification of the superfamilies Pseudocyclopoidea and Epacteriscoidea]. Zoologicheskii Zhurnal 86:671-683

Bowman TE, González JG (1961) Four new species of Pseudocyclops (Copepoda: Calanoida) from Puerto Rico. Proc US Natl Mus 113:37-59

Bradford-Grieve JM (2004) Deep-sea hyperbenthic calanoid copepods and their colonization of the near-bottom environment. Zool Stud 43:276-291

Brady GS (1872) Contributions to the study of the Entomostraca. 7. A list of the non-parasitic marine Copepoda of the north-east coast of England. Ann Mag Nat Hist 10(4):1-17 pls. 2-6

Brady GS, Robertson D (1873) Contributions to the study of the Entomostraca. 8. On marine Copepoda taken in the west of Ireland. Ann Mag Nat Hist 12(4):126-142

Brugnano C, Zagami G, Granata A (2006) Preliminary data on egg production rates of Pseudocyclops xiphophorus Wells, 1967 from the brackish lake Faro (north-eastern Sicily). Chem Ecol 22(Suppl. 1):191-195

Brugnano C, Boxshall GA, Costanzo G, Zagami G (2009) Morphological variation and a remarkable new sexual dimorphism in the Pseudocyclops xiphophorus population of Lake Faro in northeastern Sicily. Sci Marina 73:347-355

Carlton JT (1985) Transoceanic and interoceanic dispersal of coastal marine organisms: the biology of ballast water. Annu Rev Oceanogr Mar Biol 23:313-371

Costanzo G, Crescenti N, Zagami G (2004) Postembryonic development of Pseudocyclops umbraticus Giesbrecht, 1893 (Copepoda, Calanoida) from coastal waters of Sicily. Crustaceana 77:49-66

Dawson JK (1977) A new species of Pseudocyclops (Copepoda: Calanoida) from the southern California coast. Trans Am Microsc Soc 96:247-253

Esterly CO (1911) Calanoid Copepoda from the Bermuda Islands. Proc Am Acad Arts Sci 47:219-226

Ferrari FD (1995) Six copepodid stages of Ridgewayia klausruetzleri, a new species of calanoid copepod (Ridgewayiidae) from the barrier reef in Belize, with comments on appendage development. Proc Biol Soc Wash 108:180-200

Ferrari FD, Benforado A (1998) Relationships between arthrodial membrane formation and addition of setae to swimming legs 1-4 during development of Dioithona oculata, Ridgewayia klausruetzleri, Pleuromamma xiphias, and Temora longicornis (Copepoda). Crustaceana 71:545-564

Ferrari FD, Dahms HU (2007) Post-embryonic development of the Copepoda. Crustaceana Monogr 8:1-226

Ferrari FD, Ivanenko VN (2001) Interpreting segment homologies of the maxilliped of cyclopoid copepods by comparing stage-specific changes during development. Org Divers Evol 1:113-131

Ferrari FD, Ivanenko VN (2008) Identity of the protopodal segments and ramus of maxilla 2 of copepods (Crustacea). Crustaceana $81: 823-835$

Fosshagen A (1968) Marine biological investigations in the Bahamas. 4. Pseudocyclopidae (Copepoda, Calanoida) from the Bahamas. Sarsia 32:39-62

Giesbrecht W (1893) Systematik und Faunistik der pelagischen Copepoden des Golfes von Neapel und der angrenzenden MeeresAbschnitte. Fauna und Flora des Golfes von Neapel und der angrenzenden Meeres-Abschnitte, Herausgegeben von der Zoologischen Station zu Neapel 19:1-831 pls. 1-54

Gurney R (1927) Report on the Crustacea. Copepoda (littoral and semiparasitic). Zoological Results of the Cambridge Expedition to the Suez Canal, 1924, no. 35. Trans Zool Soc Lond 22:451-577

Haridas P, Madhupratap M, Ohtsuka S (1994) Pseudocyclops lakshmi, a new species (Pseudocyclopidae: Calanoida: Copepoda) from the Laccadives, India. Proc Biol Soc Wash 107:151-163

Hulsemann K (1991) The copepodid stages of Drepanopus forcipatus Giesbrecht, with notes on the genus and a comparison with other members of the family Clausocalanidae (Copepoda, Calanoida). Helgoländer Meeresuntersuchungen 45:199-224

Markhaseva EL, Dahms H-U (2004) Plesioscolecithrix (Copepoda, Calanoida, Scolecithrichidae): a new genus and a new species from the high Antarctic Weddell Sea (Southern Ocean). Sarsia 89:326-337

Markhaseva EL, Ferrari FD (2005) New benthopelagic bradfordian calanoids (Crustacea: Copepoda) from the Pacific Ocean with comments on generic relationships. Invertebr Zool 2:111-168

Nicholls AG (1944) Copepoda from South Australia. II. Calanoida, Cyclopoida, Notodelphyoida, Monstrilloida and Caligoida. Rec South Aust Mus 8:1-62

Ohtsuka S, Fosshagen A, Putchakarn S (1999) Three new species of the demersal calanoid copepod Pseudocyclops from Phuket, Thailand. Plankton Biol Ecol 46:132-147

Por FD (1971) One hundred years of Suez Canal - a century of Lessepsian migration: retrospect and viewpoints. Syst Zool 20:138-159

Sewell RBS (1932) The Copepoda of Indian Seas, Calanoida. Mem Indian Mus 10:223-407

Ummerkutty ANP (1968) Studies on Indian copepods. 16. On some rare and interesting copepods from the south east coast of India. J Mar Biol Assoc India 8:302-319

Vervoort W (1964) Freeliving Copepoda from Ifaluk Atoll in the Caroline Islands with notes on related species. Bull US Natl Mus 236: $1-431$

Wells JBJ (1967) The littoral Copepoda (Crustacea) of Inhaca Island, Mozambique. Trans R Soc Edinb 67:189-358

Yeatman HC (1975) Two rediscovered species of littoral copepods from Barbados collections. J Tenn Acad Sci 50:2-6

Zagami G, Costanzo G, Crescenti N (2005) First record in Mediterranean Sea and redescription of the bentho-planktonic calanoid copepod species Pseudocyclops xiphophorus Wells, 1967. J Mar Syst 55:67-76

Zagami G, Brugnano C, Costanzo G (2008) Pseudocyclops giussanii (Copepoda: Calanoida: Pseudocyclopidae), a new species from Lake Faro (Central Mediterranean Sea). Zool Stud 47:605-613 